\title{
TRABALHO, COTIDIANO E O PROFISSIONAL DE ENFERMAGEM: O SIGNIFICADO DO DESCUIDADO DE SI*
}

Maria Aparecida Baggio ${ }^{1}$, Filomena Maria Formaggio²

RESUMO: Estudo que objetivou compreender o significado do (des)cuidado de si dos profissionais de enfermagem. Foi utilizado o método exploratório descritivo de abordagem qualitativa. Os participantes são cinco enfermeiros, três técnicos e quatro auxiliares de enfermagem atuantes em rede pública e particular de saúde. Constatou-se, pela análise de conteúdo, que o cotidiano de trabalho contribui significativamente para o (des)cuidado. Apreende como fatores contributivos a grande demanda de atividades, exigências e tarefas a cumprir, somando-se ao serviço mal remunerado, condições de poder inquestionável de superiores, longas jornadas de trabalho, jornada dupla para garantir melhores salários, concomitantemente a não contemplação das suas necessidades básicas de ser humano bio-psico-sócio-espiritual.

PALAVRAS-CHAVE: Enfermagem; Cuidados de Enfermagem; Ambiente de trabalho; Saúde do Trabalhador.

\section{DAILY WORKAND THE NURSING PROFESSIONAL: SELF-CARELESSNESS}

ABSTRACT: Study that aimed to apprehend the meaning of self-care (lessness) among nursing professionals. It was used an exploratory descriptive method of qualitative approach. The participants are 5 nurses, 3 nursing technicians and 4 nursing assistants working for public and private health institutions. Content analysis has shown that daily work contributes significantly to care(lessness). High demand of activities, requirements, and tasks to carry out, added to poorly-paid job, the conditions of unquestionable power on the part of superiors, long working hours, double shifts in order to secure improved salaries, concomitantly with the non-contemplation of their basic human bio-psycho-socio-spiritual needs, were apprehended as contributing factors.

KEYWORDS: Nursing; Nursing Care; Work environment; Professionals’ Health.

\section{TRABAJO, COTIDIANO Y EL PROFESIONAL DE ENFERMERÍA: SIGNIFICADO DEL "DESCUIDADO"}

RESUMEN: Este estudio tuvo El objetivo de comprender el significado del (des) cuidado de sí de los profesionales de enfermería. Fue utilizado el método exploratório descriptivo de abordaje cualitativo. Los participantes son auxiliares y técnicos de enfermería y enfermeros actuantes en la red pública y particular de salud. Se verifico, por el análisis de contenido, que el cotidiano de trabajo contribuye significativamente para el (des) cuidado. Se contemplan como fatores contributivos la gran demanda de actividades, exigencias y tareas a cumplir, el trabajo mal remunerado, condiciones de poder inquestionable de superiores, largas jornadas de trabajo, doble jornada para garantizar mejores sueldos y, al mismo tiempo, la no contemplación de sus necesidades básicas de ser humano bio-psico-socio-espitirual.

PALABRAS CLAVE: Enfermería; Atención en enfermería; Ambiente de trabajo; Salud laboral.

*Este artigo é parte da dissertação de Mestrado em Ciências da Saúde Humana da Universidade do Contestado (UnC) de Concórdia, SC. Ano de defesa 2004.

${ }^{1}$ Enfermeira. Mestre em Ciências da Saúde Humana pela UnC. Mestranda do Programa de Pós-Graduação em Enfermagem (PEN) da Universidade Federal de Santa Catarina (UFSC). Bolsista do CNPq. Membro do Grupo de Estudos e Pesquisas em Administração de Enfermagem e Saúde (GEPADES) na UFSC. Florianópolis, Santa Catarina (SC).

${ }^{2}$ Doutora em Educação pela Universidade Metodista de Piracicaba-UNIMEP. Professora de Educação, Língua e Literatura. Professora Titular da Faculdade de Tecnologia de Piracicaba-SP-FATEC. Professora Titular das Faculdades Integradas Maria Imaculada, PiracicabaSP. Coordenadora da Revista de Tecnologia da Faculdade de Tecnologia de Piracicaba, Jaboticabal e Araçatuba (SP).

Autor Correspondente:

Maria Aparecida Baggio

Rua Servidão Costa, 75 - 88036-644 - Florianópolis-SC

Recebido: 30/10/07

E-mail:mariabaggio@yahoo.com.br

Aprovado: 11/04/08 


\section{INTRODUÇÃO}

É pertinente abordar a importância da relação do profissional da enfermagem com o trabalho e o seu processo de viver, ser e sentir-se saudável, na tentativa de entender como ocorre essa relação para oferecer subsídios claros e amplos que possibilitem a reflexão entre o trabalho e a saúde. O trabalho da enfermagem, em virtude de suas características, ao desenvolver o cuidado a pessoas doentes, que vivenciam perdas, dores, sofrimento e morte, expõe o profissional a situações difíceis e de desgaste emocional. Além disso, cuidar do ser cuidador tem sido pouco valorizado pelos próprios profissionais da saúde. O cuidar exige preocupação, conhecimento, dedicação ao próximo e a si mesmo e, o profissional de enfermagem possui condições e qualificação necessárias para proporcionar um ambiente de cuidado aos clientes e aos profissionais cuidadores da equipe multiprofissional.

Ao cuidador cabe - em seu cotidiano de trabalho - exercitar, sobretudo, antes de prestar o cuidado ao cliente, cuidado de si mesmo, na sua totalidade, buscando equilíbrio físico, mental e espiritual, conscientizando-se dos seus limites e fragilidades para alcançar a harmonia entre o cuidado de si e o do outro.

Assim, na esteira desse pensamento, este estudo objetivou compreender o significado do (des)cuidado de si para o profissional de enfermagem, a partir do cotidiano de trabalho.

\section{METODOLOGIA}

Trata-se de um estudo do tipo exploratóriodescritivo de abordagem qualitativa. Participaram doze profissionais de enfermagem em exercício na rede pública e particular no interior do Estado do Rio Grande do Sul, sendo quatro auxiliares de enfermagem, três técnicos de enfermagem e cinco enfermeiros, selecionados aleatoriamente, considerando-se, porém, sua disponibilidade para a participação no estudo. Para este artigo foram selecionados fragmentos de falas substanciais de dez sujeitos, identificados por nome de flores, por escolha da pesquisadora e com anuência dos participantes, garantindo, a estes, o anonimato.

A faixa etária varia de 25 a 46 anos e o tempo de atuação destes profissionais situa-se entre 3 e 26 anos.

A coleta de dados foi realizada por meio de entrevista com questões estruturadas e semiestruturadas sobre o tema em estudo. Os dados coletados foram analisados qualitativamente por meio da leitura e releitura das entrevistas de acordo com a análise de conteúdo ${ }^{(1-2)}$.

Primeiramente foi realizada uma leitura de contato dos dados coletados. Em seguida, realizaramse várias leituras do mesmo material visando maior aprofundamento das informações e, conseqüente, busca dos significados das falas dos sujeitos. Posteriormente, as unidades de registro - ou unidades de significado - foram classificadas e agregadas sendo, então, definidas e interpretadas as categorias que comandariam as especificações dos temas (unidades temáticas) ${ }^{(1)}$. Neste artigo, entretanto, considera-se importante a apresentação de uma das categorias que emergiu do estudo maior, a dissertação de mestrado, qual seja a do (des)cuidado de si.

O projeto, em conformidade com a Resolução $n^{0}$ 196/96 do Conselho Nacional de Saúde ${ }^{(3)}$ que estabelece normas e diretrizes à conduta de pesquisas que envolvem seres humanos, foi submetido à apreciação do Comitê de Ética em Pesquisa da Universidade do Contestado, bem como ao Colegiado do Curso de Mestrado, e recebeu parecer favorável para a sua execução. A adesão dos participantes ao estudo ocorreu mediante a assinatura do Termo de Consentimento Livre e Esclarecido que assegura os direitos éticos aos mesmos, inclusive o de desistir da participação na pesquisa em qualquer tempo.

\section{RESULTADOS E DISCUSSÃO}

A enfermagem, neste estudo, está representada na sua totalidade pelo gênero feminino, questão que não foi intencional, contudo, suscitou atenção na análise dos dados.

A mulher trabalhadora alia às suas atribuições profissionais, também o cuidado do lar, dos filhos, do cônjuge, como característica do trabalho feminino. Sua inserção no mercado de trabalho traz a conflitante tarefa de conciliar as atividades no espaço privado e público, a ocupação doméstica e a profissional que - a rigor é mal remunerada - e levam à dupla jornada, engendrando, nesse sentido, a exploração do gênero ${ }^{(4)}$.

A mulher, pela condição de gênero, tem seu trabalho representado como 'ajuda' no orçamento familiar vendendo sua força de trabalho, em geral, por preço inferior, se comparado ao gênero masculino. Além disso, a mulher desenvolve atividades extensivas, porém, distante das esferas de liderança ou poder ${ }^{(5)}$. Em contraponto, em inúmeras situações é a mulher a 
responsável pelo orçamento e sustento familiar, a partir do seu trabalho, realidade comum no gênero feminino da enfermagem.

O trabalho, além de fonte de rendimentos se caracteriza, também, como um elemento importante ao ser humano no que se refere a sua relação com o mundo material e à vida psíquica. No ambiente laboral, o profissional de enfermagem se relaciona com diferentes pessoas, em dimensões diversas. Nessa perspectiva, a qualidade de tais relações tende a repercutir - positivamente ou não - nos demais ambientes em que o profissional se insere.

As enfermeiras/mulheres/mães não conseguem separar a vida familiar e a vida profissional, na medida em que o trabalho de enfermagem tende a ser percebido como uma extensão do cotidiano da mulher com o cuidado da família (das crianças, do marido), não apartando de si o mundo do lar e o do trabalho( ${ }^{(6)}$.

Evidencia-se para esses profissionais a dificuldade, ou mesmo, impossibilidade, em dissociar a vida pessoal da profissional, pois o indivíduo está constantemente atento aos aspectos que lhe circundam:

A gente não consegue deixar a casa em casa e o serviço deixar no serviço e ir prá casa. Eu vejo que o tempo tá fechando, eu ligo prá casa, fecha a janela, oh, vai dar temporal, tira das tomadas. Tem sol, digamos. Olha, estendi as roupas na garagem, bota pro sol. Quem é que busca a [filha] na escola hoje? A vida da gente é uma só. Talvez tenha pessoas que consigam separar, mas eu acho que é difícil. Separar [...] acho que ninguém consegue (Tulipa).

Ao passar por quaisquer dificuldades - pessoais ou ocupacionais - $\mathrm{o}$ trabalhador de enfermagem sentese impotente para delimitá-los, permitindo que, via de regra, interfiram tanto na vida pessoal quanto na profissional, como apontam os relatos a seguir:

Eu tô enfrentando um monte de coisa, que eu não tô sabendo separar. [...] é muita coisa em casa e eu não consigo [...]. Então eu fico preocupada com o serviço e com minha pessoa [...] (Camélia).

Eu já não conseguia mais separar o lado emocional assim. Prá ser bem sincera. Não consigo. Profissionalmente eu trabalho porque tu sabe, tem que trabalhar. Agora se tu lida com emoções das pessoas [...] tu sabe que tu tem uma ligação, sabe automático, tem uma ligação (Violeta).

Invariavelmente os problemas advindos do trabalho acabam preocupando o profissional, relegando sua vida pessoal a um segundo plano. No local de trabalho o nervosismo e a ansiedade precisam ser contidos e, as palavras, (re)avaliadas para evitar desentendimentos com sujeitos da equipe multiprofissional.

No entanto, o profissional, em muitos casos, pode descarregar toda a sua agressividade e indignação no seu próprio lar, pois precisa desabafar de alguma forma. Às vezes, os filhos, o marido, o pai, a mãe ou outra pessoa próxima pode ser agredida ou insultada sem merecer, por servir de válvula de escape para os problemas oriundos do ambiente de trabalho. Os depoimentos a seguir são expressivos neste sentido:

Por se estressar tanto no serviço, a gente chega em casa e estoura tudo em casa. Que no serviço tu não pode misturar o lado profissional com o pessoal. E aí tu chega em casa e descarrega tudo [...]. Como hoje, foi um dia que eu saí do hospital, que parei no vestiário, senti vontade de chorar. Tava uma pilha. E às vezes a gente acaba, sei lá, eu noto, eu às vezes eu acabo absorvendo muita coisa e que acaba, como eu disse antes, cuidar prá não levar as coisas prá casa [...] a gente leva. Às vezes eu estou em casa e me lembro: me incomodei com o Dr. Fulano de tal e ele me disse isso, isso e isso e eu fico com aquilo? Ah, ele está lá na casa dele dormindo, se divertindo com os amigos e não tá nem aí prá mim, nem lembra que eu existo e eu aqui sofrendo por causa disso. Então, tem às vezes, tem umas coisas que me angustiam, daí eu tento dispersar (Tulipa).

O trabalho é, para alguns, motivo de preocupação em tempo integral. Certas questões existentes no ambiente laboral são absorvidas pelo profissional como um problema individual, que o perturba mesmo nas horas de folga. Ele se esquece da co-responsabilidade dos demais; assume a responsabilidade sozinho e abandona o cuidado de si em prol do trabalho.

Alguns depoimentos são enfáticos nesta perspectiva:

Às vezes, a gente não consegue separar o trabalho da vida pessoal [...] eu não consigo. E automaticamente a gente acaba associando, por 
mais que tente, às vezes... [...]. Acho que eu me preocupo bastante com o trabalho. Não tanto de lá com a casa, mas como, em casa com o trabalho. Que a gente não consegue se desligar, a gente fica sofrendo [...]. É que a gente carrega prá si como se fosse os da gente, mas não são, são do local que a gente está (Orquídea).

A tensão entre a vida pública-trabalho e a privada-familiar aponta a incompatibilidade entre ambas e que se traduz, muitas vezes, em insatisfações e frustrações. O profissional precisa optar pelo que é mais importante para a sua vida, situação esta que se configura por conflitos simultâneos entre trabalho e família ${ }^{(6)}$.

O trabalhador que procura separar as preocupações pessoais das profissionais considera que as pessoais são mais fáceis de controlar, pois o trabalho gera, no mais das vezes, inquietações. Admitem, entretanto, a complexidade da questão e reconhecem a interferência do profissional em casa e na família. Os relatos a seguir explicitam tal situação:

Eu procuro não misturar as coisas [...] se eu tenho algum problema pessoal dificilmente eu comento com alguém dentro do meu trabalho, dificilmente. Eu procuro separar bem as coisas. É difícil você não deixar transparecer, mas a gente tenta. Eu procuro não misturar as coisas. No trabalho não. Em casa até acho que sim. Porque em casa a gente fica sem paciência. Então, se eu não estou bem, até as crianças percebem. Mas no trabalho eu procuro separar. É a posição que a gente ocupa (Helicônia).

Tem dias que é quase impossível sair do trabalho e esquecer o que ficou ou aquilo que você fez ou algo que saiu errado. É quase impossível, então interfere mesmo no outro dia. Você fica praticamente um dia afastada do teu trabalho [no final de semana] e você ainda leva prá casa um pouco disso. Eu acho que fica um pouco complicado separar. O trabalho interfere muito quando a gente mistura, leva pra casa. Às vezes é quase impossível não levar (Bromélia).

Há profissionais que acreditam ser possível dissociar o trabalho da vida pessoal, de modo que um não prejudique o outro. A vida pessoal, na percepção de alguns, não deve invadir a vida profissional. Mas será que é mesmo possível?
No meu caso, eu acho que eu até conseguia, quer dizer, não que conseguia, não chegava atingir a minha, como é que eu vou dizer? Me atingir profissionalmente. Eu acho que o descuidado que eu tava tendo comigo eu conseguia, não acabava assim, não misturava com o meu trabalho [...] (Lírio).

Quando o indivíduo faz parte de uma organização, ele ocupa um cargo e desempenha uma função específica, de acordo com a divisão do trabalho. Os sujeitos desta pesquisa afirmam existir um determinado sofrimento causado pela pressão, normas, condutas e cobranças vivenciadas em seu trabalho.

A não flexibilização no trabalho que não permite ao trabalhador o emprego das suas aptidões individuais e adequar sua estrutura física e psíquica ao trabalho e aos seus desejos, vontades e anseios. Isso, indubitavelmente, acarretará insatisfação e desprazer ao trabalhador ${ }^{(7)}$. Todavia, as organizações necessitam demonstrar preocupação com o cuidado destes que se dispõem a cuidar de tantos, pois a qualidade final das empresas está vinculada à qualidade de vida dos trabalhadores $^{(8)}$.

Uma organização do trabalho em que prevalece o modo autoritário e centralizador do poder e não permite ao trabalhador o desempenho da sua autonomia, desmotiva o desenvolvimento das suas atividades pois, muitas vezes, esse trabalhador desempenha ou realiza ações das quais discorda ou acredita que poderia ser realizada de modo diferente. Desenvolver as atividades profissionais contrariando os seus princípios causa sofrimento ao trabalhador que tem a sua culpa acentuada ao não poder dizer, não. Certas atividades realizadas pelo profissional em seu trabalho provocam fadiga, dor, desgosto, rotina e pesar $^{(9)}$. O desejo, talvez, seria parar imediatamente as atividades que causam tais sentimentos mas, possivelmente, não param, porque são forçados pela necessidade, pelas ameaças; quem sabe, pela falta de coragem. Alguns depoimentos dos sujeitos apontam tal situação:

Porque a pressão no serviço, é sempre grande (Tulipa).

Quanto às normas dentro da instituição [...]. Determinadas normas, determinadas condutas, determinadas funções que a gente tem que tomar [...]. Coisas assim que mexem contigo e não tem como atuar, agir. Tu não tem autonomia, tá ali dentro 
da tua função. São determinados papéis pra ti, e tem que seguir aquilo. Acho que aquela pressão, aquela cobrança, dentro de uma coisa que às vezes tu não, não, não é que não aceita, não [...] como é que eu vou dizer, não [...] (Orquídea).

O poder constitui uma trama difusa. Ele classifica, individualiza, totaliza e subjuga os sujeitos por sistemas de controle e dependência. Em muitos casos, a enfermagem mostra-se submissa, sujeitandose a quem representa o poder, tornando-se passível ao controle externo, à vontade de outro para a tomada de decisões, cumprindo normas, determinações e ordens ‘inquestionáveis’. Muitas ações praticadas pela enfermagem são oriundas ou determinadas pelo sentimento de medo, insegurança, passividade e conformismo a quem representa o poder ${ }^{(10)}$.

É realidade no cenário de algumas instituições o exercício de práticas gerenciais de forma menos rígidas e hierarquizadas e mais ágeis e flexíveis. No entanto, a enfermagem, no cotidiano de sua prática necessita pensar/repensar/discutir/analisar a estrutura organizacional clássica ainda existente e o gerenciamento ainda pautado em princípios tayloristas, a fim de acompanhar as demandas atuais que denotam preocupação com o viver e conviver saudavelmente no espaço organizacional ${ }^{(11)}$.

Nessa perspectiva, a organização do trabalho de enfermagem precisa ser repensada, no sentido de imprimir à vida do trabalhador um sentido mais humano, visto que a sua realidade profissional possui um modo impositivo, inflexível, repleta de normatizações inquestionáveis ${ }^{(12)}$. Tal situação tem gerado angústia e, ao mesmo tempo, certa impotência, conforme mostra o relato a seguir:

Mas aquilo que tu não pode mudar [...] aquilo que tu não consegue, não adianta. Tu vai bater de frente com normas da instituição, com o pensamento que vem de outras pessoas que estão acima de ti. Tudo o que eu posso mudar eu tento fazer melhor. A não ser, que eu sei que não depende de mim. Eu estou procurando ficar mais um pouco tranqüila. É difícil no início, mas depois [...]. Mas aquilo que eu sei que eu não consigo é bom separar assim, o que cabe a ti e aquilo que não cabe a ti. Tu sempre vai encontrar esse tipo de situação. [...] Então, aquilo que depende de mim eu mudo. Mas aquilo que não depende, o que eu posso fazer? (Bromélia).
Apesar das transformações e avanços ocorridos na modernidade, prevalece nos dias atuais, na área da enfermagem, uma ética alienada e anti-reflexiva, que determina uma posição conformista e passiva dos sujeitos.

O profissional tende a se conformar com a situação encontrada, talvez para minimizar o seu sofrimento. Esse trabalhador tenta aceitar a sua limitação evitando o confronto com a organização, pois acredita que, para aquilo que não consegue mudar, não adianta 'bater de frente', principalmente em se tratando de pessoas que ocupam cargos superiores ao seu.

Parece cômodo manter-se na minoridade, a espera pelo pensar e decidir do outro, pois não exige a necessidade de refletir ou de se posicionar perante qualquer situação. No entanto, o homem é o único responsável pelo seu estado de minoridade e, sair dessa situação, somente será possível, se a mudança for operada por si mesmo.

Vale lembrar que o homem é um sujeito dotado de ética e moral, possuidor de crenças, valores e vontades, não devendo subjugar-se a princípios que não são aceitos ética e moralmente por si. A reflexão sobre si mesmo como sujeito, ser pensante que é, participante da sociedade constitui o princípio da ação para as transformações sociais necessárias, como aponta o relato a seguir:

Tu não pode, tem que se cuidar [...] como coisa, tu vai ser prejudicada profissionalmente [...] as pessoas têm medo no trabalho. Medo [...] medo de fazer alguma coisa errada. Medo! Competitividade também (Violeta).

O medo e a insegurança explicitados pelo sujeito nos leva a concordar com a afirmação que "o trabalho [...] é um paraíso criativo para poucos e um castigo penoso, nocivo, banal, repetitivo e competitivo para muitos $[\ldots]]^{\prime(9: 41)}$.

A competitividade profissional é uma forma de violência no trabalho entre os colegas, levando à desvalorização, à desmotivação do grupo e, principalmente, à desintegração dos profissionais no ambiente em que convivem ${ }^{(13)}$.

As relações de poder são inerentes ao ambiente de trabalho, portanto, indissociáveis, social e culturalmente, onde existem estruturas hierárquicas. O poder, enquanto processo social é vital e necessário; entretanto, pode ser considerado perigoso no momento em que essas relações se tornam um modo de 
dominação de uns sobre os outros. O uso do poder, sem considerar os aspectos humanos na relação chefesubordinado, desencadeia insatisfação no ambiente de trabalho. O poder exercido, que não considera os desejos e necessidades dos trabalhadores hierarquicamente subordinados, está conduzindo a um sofrimento que poderia ser evitado se houvesse compreensão por parte das chefias ${ }^{(12)}$. A citação ilustra,

o ser humano parece em constante conflito entre ter e ser e o ter associado ao poder, no sentido de domínio, força e controle. Dessa forma, para demonstrar o seu poder, equivocadamente pensado como um atributo do ser, os humanos buscam adquirir coisas e bens, e dominar coisas e pessoas. Com isso demonstram sentimentos de não cuidado $[\ldots]^{(14: 18)}$.

Não se pode desprezar a organização do trabalho, percebida como indispensável à nossa sobrevivência e ao progresso humano e das instituições, mesmo que muitas chefias se comportem de modo desconcertante e estúpido. Porém, algumas discrepâncias encontradas em certas organizações acarretam mal-estar aos indivíduos que, por sua vez, o disseminam a todos os ambientes de trabalho nos quais convivem ${ }^{(9)}$.

Em estudo sobre a governabilidade a partir de Foucault, Lunardi ${ }^{(15)}$ estabelece a forma de 'poder', como sendo 'relações de poder' formadas por diversas forças do âmbito social, familiar, escolar e de diferentes grupos e instituições e que lhes fomenta o alicerce e a sustentação. O poder advém de forças produtivas dessas relações de forma contínua e permanente. Foucault visualiza o poder como uma possibilidade, um processo em que as pessoas envolvidas possam ser mais livres do que pensam ser.

Eu não consigo nem olhar pra cara dela [se referindo à chefia de enfermagem]. Até hoje eu não consigo olhar pra cara dela, eu não suportava assim [...] eu acho que ela também deve ter muitos problemas pra ser do jeito que ela é [...] eu não vejo ninguém dizer: que chefe modelo! Eu não vi nenhuma pessoa falar isso [...] Ela não compreende ninguém, ela não é humana. Todas as avaliações dela, só pra ti ter uma idéia, eu recém tinha entrado, fazia quatro meses que eu entrei no hospital, a Fulana saiu chorando de lá [da avaliação]. Meu Deus! Eu fiquei pensando: o que ela falou pra Fulana? Eu tava indignada com ela! Ela te deixava [...] eu acho que tu é assim, tu é assado, é regular, é isso, é aquilo, sabe? Bem fria sabe? (Violeta).

É possível perceber que algumas enfermeiras abordadas nesta pesquisa se mostram submissas a quem representa o poder. Por outro lado, são autoritárias com quem não o representa, desconsiderando, de certa forma, os sentimentos e valores humanos na relação com os subordinados. Será que é este o tratamento que a enfermagem quer que seja a si dispensado?

Uma palavra ou um gesto pode deixar o profissional desmotivado, arrasado, deprimido levandoo ao descontentamento e à desesperança. Quando esses sentimentos são provenientes de atitudes, de tratamentos dispensados pelas chefias, a frustração é ainda maior.

$O$ relacionamento interpessoal no ambiente de trabalho é manifestado pelos profissionais como difícil de ser prazeroso, pois existem problemas de convívio e de comunicação entre os mesmos. Mas, deve-se salientar que, cada indivíduo é responsável pelo estabelecimento da harmonia no seu trabalho, devendo, para tal, estabelecer uma relação profissional calcada no respeito para manter um ambiente satisfatório.

Acho que não é porque você é chefe, que você tem o direito de pisar nos outros. Falta de respeito! Falta de respeito de funcionários, de outros funcionários com a chefia acontece [...]. Já vi chefia solicitar serviço particular. $O$ empregado não é teu, é da empresa. Abuso do poder! O ambiente profissional é difícil de ser prazeroso na nossa área, infelizmente (Ipê).

Percebe-se o abuso e a dominação pelo poder de algumas chefias, que delegam funções aos profissionais desviando-os a atividades distintas para as quais não foram, pela empresa, contratadas. Qual seria o posicionamento ético adequado do profissional subordinado frente a uma situação semelhante à exposta?

Trazer à tona as relações de poder vivenciadas e percebidas no ambiente de trabalho como eticamente incorretas seria um meio de valorizar-se como ser humano e profissional. Conquistar a participação ativa nessas relações seria uma forma de cuidado de $\mathrm{si}^{(12)}$.

O profissional, muitas vezes, faz dupla jornada de trabalho e horas extras para garantir o seu padrão de vida e o sustento da família. A saúde deste trabalhador é constantemente bombardeada por preocupações financeiras que dilaceram o ser humano, pois o obrigam 
a realizar inúmeras horas de trabalho com a intenção de multiplicar a sua renda expondo sua saúde a riscos de diversas naturezas ${ }^{(12)}$. Dessa forma, na busca do estilo de vida almejado, o profissional que se submete a realização de jornadas excessivas de trabalho, em contrapartida, se afasta do convívio familiar e social, ficando exposto ao estresse e a irritabilidade ${ }^{(16)}$.

Tal situação, nos remete a uma questão crucial: se a remuneração na enfermagem fosse adequada e condizente com a importância da profissão, possivelmente não obrigaria o profissional a enfrentar várias jornadas de trabalho para melhorar a sua renda e não sacrificaria o seu tempo, possibilitando-lhe, certamente, algum tempo livre ao cuidado de si. Esta questão é abordada no relato a seguir:

A enfermagem eu acho que ela é muito mal remunerada. Eu acho que não é gratificante o nosso trabalho de enfermagem no sentido de dinheiro. Em outras coisas você ganha muito, passa muito, mas você ganha muito. É gratificante no sentido assim de ganhar e passar, mas assim em termos financeiros não. Por isso que se tem, que eu tenho outro trabalho. Eu tenho mais de um trabalho pra manter o padrão de vida que a gente gostaria e quer, trabalha assim e daí acaba se descuidando (Rosa).

A remuneração do trabalho da enfermagem gera desânimo ao profissional devido às restrições impostas a sua vida particular, obrigando o indivíduo a trabalhar em mais de um emprego para garantir uma condição melhor de vida. Esse quadro reflete a desvalorização do trabalho da enfermagem levando em consideração o tipo de atividade exercida e as responsabilidades inerentes à profissão ${ }^{(17)}$.

É possível notar, pelos relatos de alguns profissionais de enfermagem, que o trabalho, conforme determinadas condições (carga horária excessiva, baixa remuneração, ordens incontestáveis), pode gerar insatisfação e sofrimento. No entanto, consideram que é muito prazeroso atuar na enfermagem em que, a recompensa, advém do cuidado prestado. O prazer obtido da relação de cuidado ao outro compensa, em geral, os desprazeres encontrados na profissão.

O profissionalismo e a responsabilidade do cuidador de enfermagem, especialmente dos sujeitos deste estudo, exaltam a profissão. O compromisso ético e moral com o cliente é evidenciado pelos cuidadores, assim como o orgulho e a satisfação pelo compromisso assumido com o cuidado do outro, como apontam os relatos a seguir:

Olha, o profissional eu faço o possível pra no trabalho tá bem sempre [...]. Fazer como deve ser feito e atender bem os pacientes (Camélia).

Eu tenho uma coisa assim comigo, que é ser responsável. Por exemplo, no meu trabalho eu procuro ser o mais eficiente possível. [...] não admito trabalhar ali na sala de vacina e eu não saber responder uma questão sobre vacinas, sabe? Então, sempre que surge uma novidade, uma dúvida, eu vou atrás da resposta. Então, eu sou muito interessada no meu trabalho, a mesma coisa assim em casa. Eu sei que eu tenho que cuidar bem dos meus filhos, da casa, então, eu procuro fazer o máximo (Helicônia).

Acho assim, que o que eu tô fazendo ali, o que eu faço é pro paciente [...] eu me sinto bem fazendo isso. Eu gosto do que eu faço, sempre gostei. Quando eu fazia o curso o pai disse: "porque você não vai fazer outra coisa em vez de fazer isso aí?" Eu gosto muito do que eu faço, por mais que, às vezes, tu fica estressada. Mas eu gosto. Eu gosto mesmo do que eu faço (Margarida).

\section{CONSIDERAÇÕES FINAIS}

O estresse vivenciado no cotidiano de trabalho parece ter origem no círculo vicioso de trabalho, desgaste, trabalho, desgaste [...]. Os sujeitos manifestam que o ambiente de trabalho contribui significativamente para o (des)cuidado, dada a grande demanda de atividades, exigências e tarefas a cumprir.

As queixas dos profissionais são relacionadas ao serviço mal remunerado, condições de poder inquestionável de superiores, longas jornadas de trabalho, jornada dupla para garantir melhores salários, concomitantemente a não contemplação das suas necessidades básicas de ser humano bio-psico-socioespiritual que remete ao (des)cuidado de si.

Constatamos, dessa forma, que as instituições de saúde são direta e indiretamente responsáveis pelos desajustes psíquicos e físicos apresentados pelo trabalhador de enfermagem. Em virtude de tal constatação é fundamental que as instituições assumam o compromisso, também, com o cuidado dos seus profissionais e, ainda, estimule hábitos e atitudes saudáveis, fomentando em seu espaço condições 
saudáveis de relacionamento. Com essa iniciativa seria possível diminuir a probabilidade de comprometimentos à saúde dos funcionários. Conseqüentemente, o retorno, além de pessoal, institucional, é ainda social, pois o trabalhador com o corpo e a mente sãos propiciará ao cliente uma prestação de serviço com qualidade.

Assim, entendemos que há a impossibilidade de dissociar o trabalho da vida pessoal. Dessa forma, necessário se faz que o profissional de enfermagem assuma o cuidado de si no âmbito pessoal e profissional com a mesma responsabilidade com que cuida do outro. Por outro lado, é preciso reconhecer os próprios limites e fragilidades para saber atuar de forma a não ferir as próprias convicções, anseios e desejos e, consequentemente, atingir o exercício pleno da profissão.

$E$, à guisa de conclusão, frente às relações de poder evidenciadas, pertinente se faz que os profissionais de enfermagem, por meio de atitudes e comportamentos, resgatem a sensibilidade, a empatia e a generosidade, conciliadas à razão, à ciência para o desenvolvimento de uma prática profissional agradável e à convivência algo prazerosa.

\section{REFERÊNCIAS}

1. Minayo MCS, organizadora. Pesquisa social: teoria, método e criatividade. 20ª ed. Petrópolis: Vozes; 2002.

2. Minayo MCS. O desafio do conhecimento: pesquisa qualitativa em saúde. 10a . ed. São Paulo: Hucitec/ Abrasco; 2006.

3. Ministério da Saúde (BR). Conselho Nacional de Saúde. Diretrizes e normas regulamentadoras de pesquisa envolvendo seres humanos. Resolução n ${ }^{\circ} 196$, de 10 de outubro de 1996. Brasília; 1996.

4. Rabello SB, Godoy CVC, Padilha WWN. Por que a Odontologia se transformou numa profissão de mulheres? Rev Bras Odontol. 2000 Mar/Abr [acesso em 2004 Ago 22]57(2). Disponível em: www.odontologia.com.br/artigos.

5. Fischer IR, Marques F. Gênero e exclusão social [página na internet]. Recife (PE): Ministério da Educação. Fundação Joaquim Nabuco - Trabalhos para discussão, 2001 Ago [acesso em 2004 Set 24]n.113. Disponível em: www.scielo.br.

6. Fernandes JD, Ferreira SL, Albergaria AK, Conceição FM. Saúde mental e trabalho feminino: imagens e representações de enfermeiras. Rev Latino-Am Enferm.
2002 Mar/Abr [acesso 2004 em Set 20]10(2). Disponível em: www.scielo.br.

7. Dejours C. A loucura do trabalho - estudo de psicopatologia do trabalho. $5^{a}$ ed. São Paulo: CortezOboré; 1992.

8. Costenaro RGS, Lacerda MR. Quem cuida de quem cuida? Quem cuida do cuidador? Santa Maria: UNIFRA; 2001

9. De Masi D. O futuro do trabalho: fadiga e ócio na sociedade pós-industrial. Brasília: UNB - José Olympo; 2000.

10. Lunardi VL. Do poder pastoral ao cuidado de si: a governabilidade na enfermagem [tese]. Florianópolis (SC): Universidade Federal de Santa Catarina; 1997.

11. Spagnol CA, Fernandes MS. Estrutura organizacional e o serviço de enfermagem hospitalar: aspectos teóricos. Rev Gaúcha Enferm. 2004;25(2):157-64.

12. Costa ALRC. O cuidado como trabalho e o cuidado de si no trabalho de enfermagem [dissertação]. Florianópolis (SC): Universidade Federal de Santa Catarina; 1998.

13. Dias HHZR. O “des” cuidado em saúde: a violência visível e invisível no trabalho de enfermagem [dissertação]. Florianópolis (SC): Universidade Federal de Santa Catarina; 2002.

14. Waldow VR. Cuidado humano: o resgate necessário. Porto Alegre (RS): Sagra Luzzatto; 1998.

15 Lunardi VL. A governabilidade em Foucault. In: Caponi S, Padilha MICS, organizadores. A saúde em questão: um espaço para a reflexão. Florianópolis (SC): Ed. dos Autores; 1999.

16. Cecagno D, Gallo CMC, Cecagno S, Siqueira HCH. Qualidade de vida e o trabalho sob a ótica do enfermeiro. Cogitare Enferm. 2002; 7(2):54-9.

17. Lunardi Filho WD. Prazer e sofrimento no trabalho: contribuições à organização do processo de trabalho da enfermagem [dissertação]. Porto Alegre (RS): Universidade Federal do Rio Grande do Sul; 1995.

18 Baggio MB. O (des)cuidado de si do profissional de enfermagem [dissertação]. Concórdia (SC): Universidade do Contestado; 2004. 